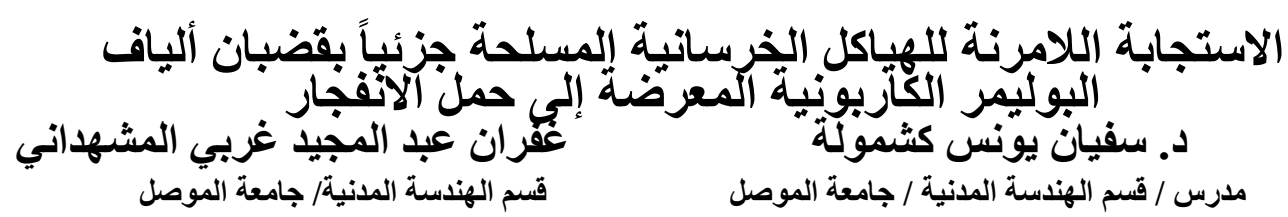

الخلاصة

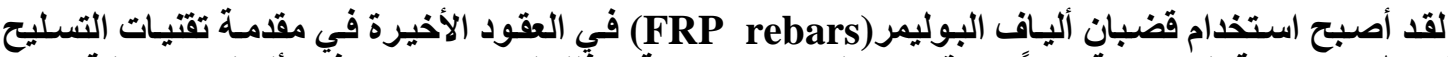

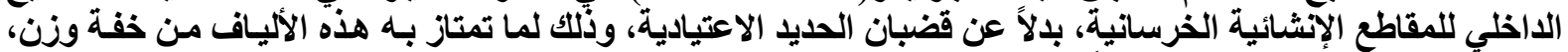

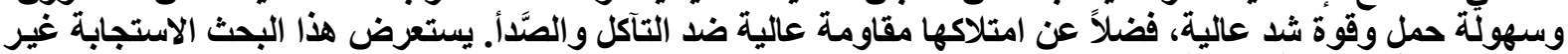

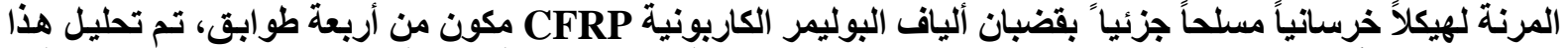

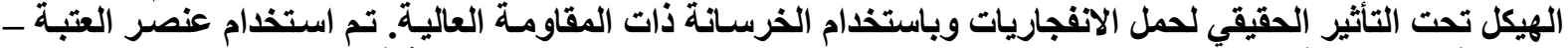

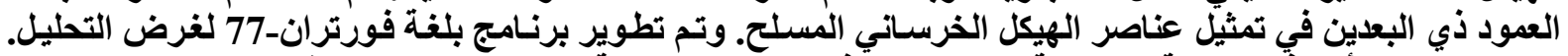

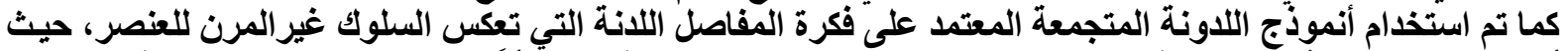

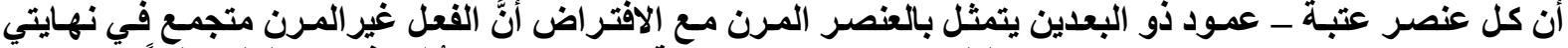

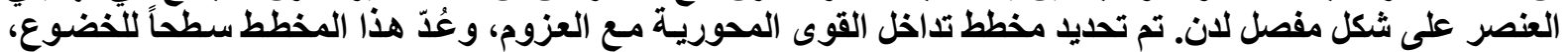

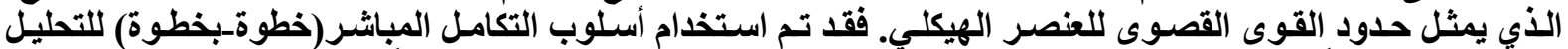

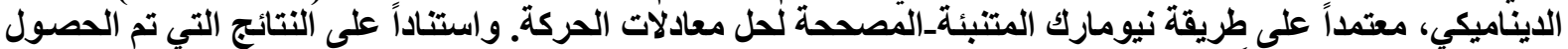

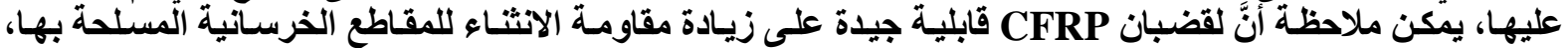

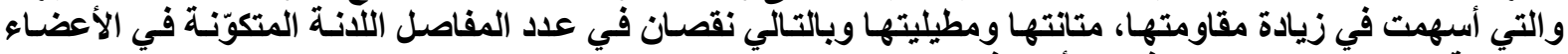
الإنثائية للهيكل الخرساني، وكذلك التأخير في زمن تكوّنها.

\title{
Inelastic Response of Reinforced Concrete Frames Partially Reinforced with (CFRP) Rebar Subjected to Blast load
}

\author{
Dr. Sofyan Younis Kashmola \\ Civil Engineering Department \\ Mosul University
}

Ghofran Abd-Almageed Gharbi

\begin{abstract}
The use of FRP rebars has become in the last decades at the head technologies of internal reinforcement of concrete sections instead of normal steel bars for their lightweight, portability and have a high tensile strength in addition to their resistance to rust and corrosion. This paper presents the inelastic response of 4-story reinforced concrete frame partially reinforced with Carbon FRP rebars. This frame was analyzed under actual blast load using high strength concrete. Two-dimensional Beam-Column Element has been used in representing the frame members. A computer program has been developed (in Fortran-77) for analysis purposes. Lump plasticity model has also been used, which depends on the concept of plastic hinges that reflect the inelastic behavior of the element, assuming that inelastic action is lumped at both ends of the element as plastic hinges. An interaction diagram between axial forces and moments is determined; this diagram is considered as a Yield Surface which represents the limits of the ultimate strength of the element. A direct Systematic integration technique has been used depending on Newmark's Predictor-Corrector method to solve the equation of motion. Based on the results obtained, it can be seen that CFRP rebars have the ability to increase the flexural resistance of reinforced concrete sections, which contributed to the increase in their strengths and their ductility; consequently, they reduce the number of plastic hinges formed in the frame, as well as delay in the time of their formation.
\end{abstract}

Keywords: inelastic response, concrete frames, carbon fiber reinforced polymer (CFRP) rebar, high strength concrete 


\begin{tabular}{|c|c|}
\hline \multicolumn{2}{|l|}{ ثبت الرموز } \\
\hline التعريف & 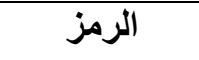 \\
\hline مساحة قضبان ألياف البوليمر الكلية & $A_{f}$ \\
\hline مساحة قضبان ألياف البوليمر للطبقة ز & $A_{f i}$ \\
\hline مساحة قضبان حديد التسليح الكلية & $A_{s}$ \\
\hline مساحة قضبان حديد التسليح للطبقة i & $A_{s i}$ \\
\hline الثو ابت الحدودية التي تعرف معادلة منحني التداخل بين القوى المحورية و العزم & $a_{i}$ \\
\hline عرض المقطع الخرساني المسلح لعنصر الثيكل & $\boldsymbol{b}$ \\
\hline عمق المقطع الخرساني المسلح لعنصر الهيكل & $d$ \\
\hline دالة الخضوع & $f$ \\
\hline متجه القوة الخارجية المسلطة & $\boldsymbol{F}$ \\
\hline مقاومة الانضغاط القصوى المحورية للخرسانة & $f_{c}^{\prime \prime}$ \\
\hline إجهاد الثد لقضبان ألياف البوليمر إلئ & $f_{f}$ \\
\hline إجهاد الثد الأقصى لقضبان ألياف البوليمر & $f_{f u}$ \\
\hline إجهاد الخضوع لحديد التسليح & $f_{y}$ \\
\hline عمق محور التعادل للمقطع الخرساني المسلح & kd \\
\hline مصفوفة الصلابة المرنة للعنصر الهيكلي حسب المحاور المحلية & $K_{e}$ \\
\hline مصفوفة الصلابة المرنة_اللانة لعنصر الهيكل & $K_{e p}$ \\
\hline مصفوفة الصلابة اللدنة المحلية لعنصر الهيكل & $K_{p}$ \\
\hline مصفوفة الكتلة للمنشأ & $M$ \\
\hline عدد طبقات قضبان التسليح في المقطع العرضي المسلح ع & $n$ \\
\hline القوة المحورية غير البعدية القصوى المسلطة التي يتحملها المقطع الخرساني المسلح مع وجود العزم & $p_{u}$ \\
\hline قوة الانضغاط المحورية غير البعدية التي يتحملها المقطع الخرساني المسلح في غياب العزم & $p_{o}$ \\
\hline قوة الثند المحورية غير البعدية التي يتحملها المقطع الخرساني المسلح في غياب العزم & $p_{t}$ \\
\hline القوة المحورية غير البعدية المتوازنة & $p_{u b}$ \\
\hline القوى العقدية في العنصر الهيكلي بالاتجاهات (z,y,x) & $P_{x}, P_{y}, M_{Z}$ \\
\hline درجة الحرية بالَاتجاهات الأفقية و العمودية ودور ان اللي على التو الي & $u, v, \theta$ \\
\hline متجه الإزاحة و السر عة و التعجيل على التو الي & $u, \dot{u}, \ddot{\mathrm{u}}$ \\
\hline انفعال الليف عند الحافة العليا & $\varepsilon_{t}$ \\
\hline انفعال الليف عند الحافة السفلية & $\varepsilon_{b}$ \\
\hline انفعال الخرسانة & $\varepsilon_{c}$ \\
\hline الانفعال المقابل لمقاومة الانضغاط القصوى للخرسانة & $\varepsilon_{0}$ \\
\hline انفعال الخضوع لحديد التسليح ا & $\varepsilon_{y}$ \\
\hline الإجهاد في الخرسانة وطبقة قضبان حديد التسليح في المقطع الخرساني المسلح & $\sigma_{c}, \sigma_{s}$ \\
\hline 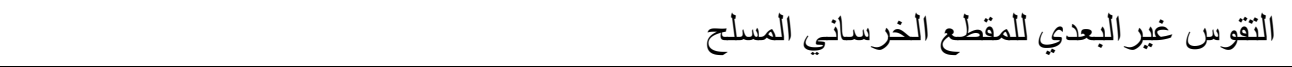 & $\phi$ \\
\hline تقوس المقطع الخرساني المسلح & $\chi$ \\
\hline نسبة مساحة قضبان حديد التسليح للطبقة العليا & $\rho_{t}$ \\
\hline نسبة مساحة قضبان حديد التسليح للطبقة السفلية & $\rho_{b}$ \\
\hline نسبة مساحة قضبان ألياف البوليمر الكلية & $\rho_{f}$ \\
\hline نسبة مساحة قضبان ألياف البوليمر للطبقة ز في المقطع الخرساني المسلح & $\rho_{f j}$ \\
\hline نسبة مساحة قضبان حديد التسليح للطبقة i في المقطع الخرساني المسلح & $\rho_{s i}$ \\
\hline كثافة الخرسانة المسلحة & $\rho_{\text {r.c }}$ \\
\hline
\end{tabular}




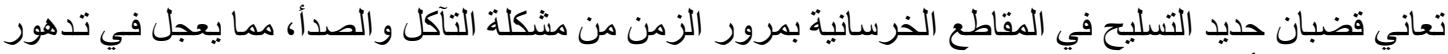

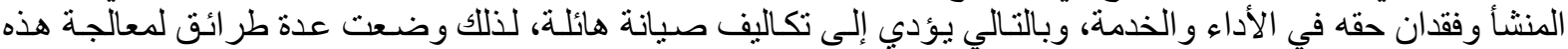

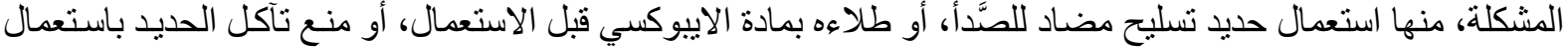

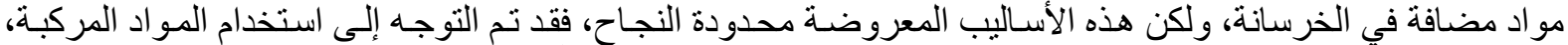

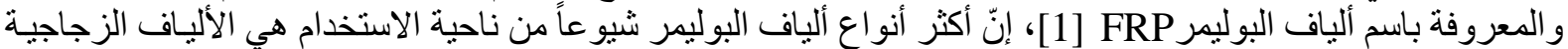

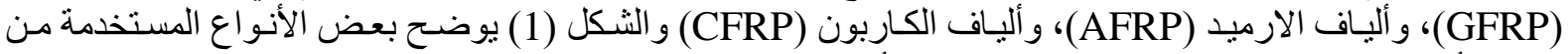

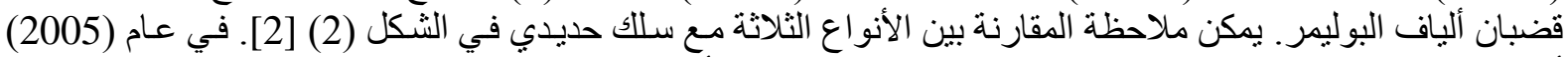

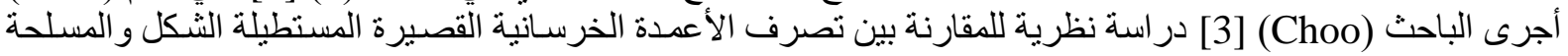

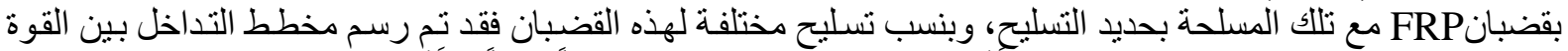

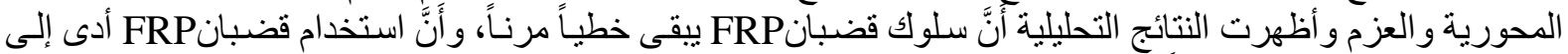

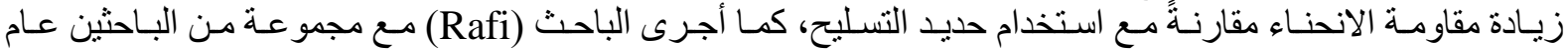

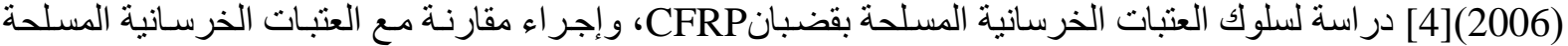

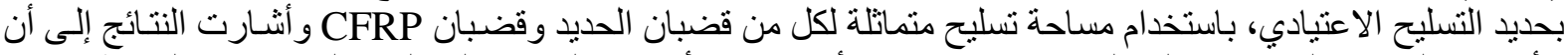

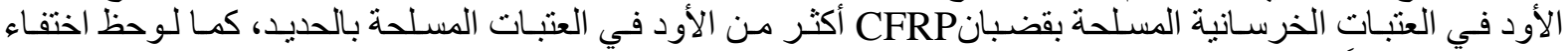

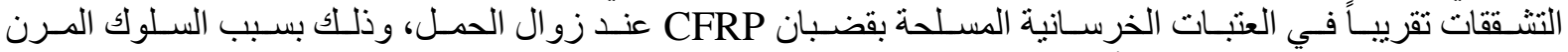

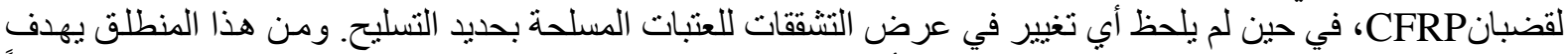

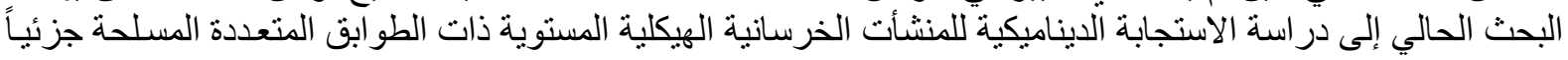
بقضبان CFRP باستخدام الخرسانة ذات الإلين المقاومة العالية.

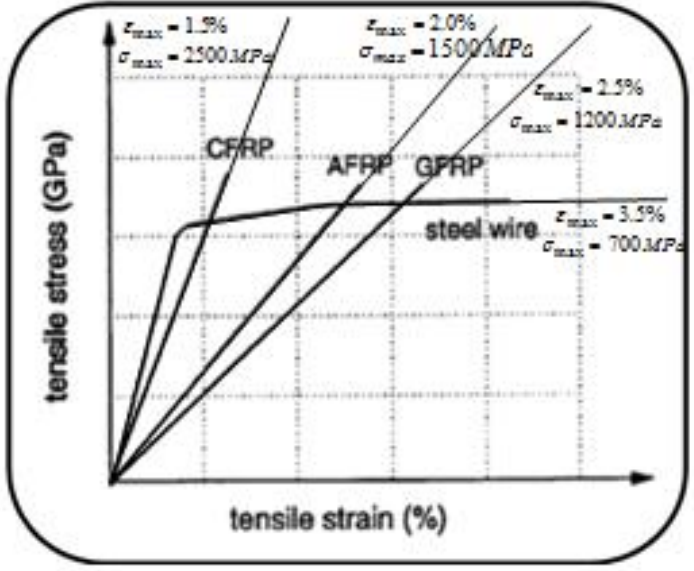

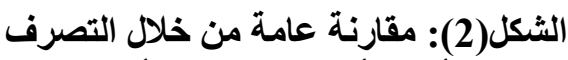
بين أنواع ألياف البوليمر الأكثر

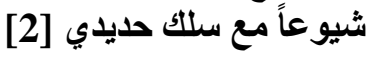

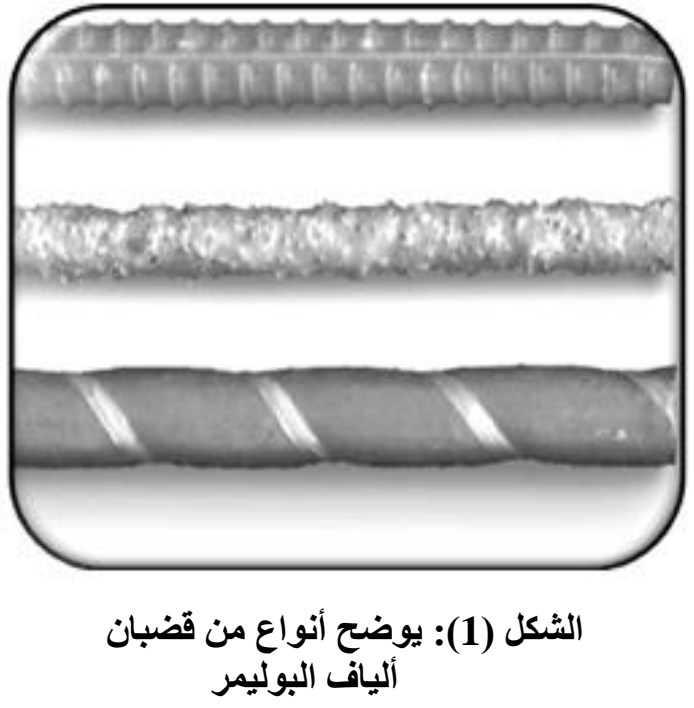

الأُنموذج الرياضي

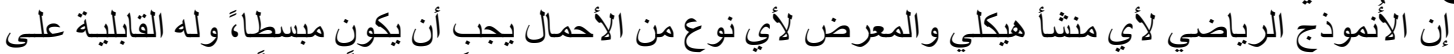

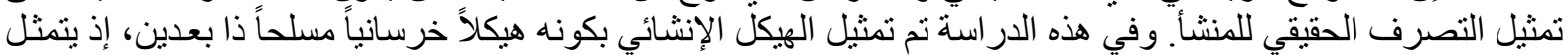

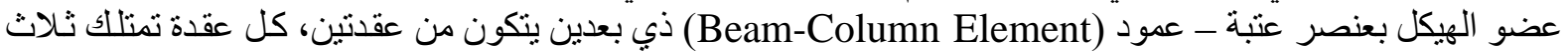

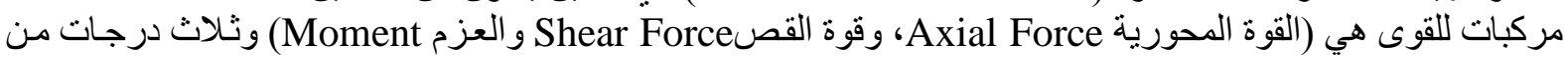

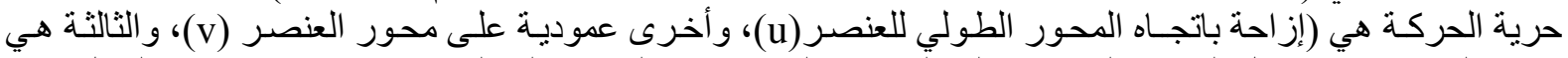

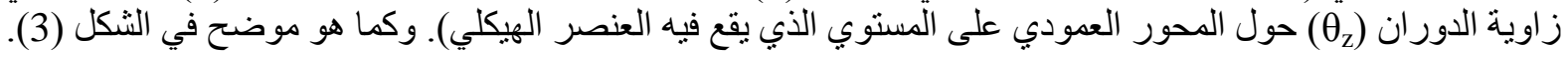

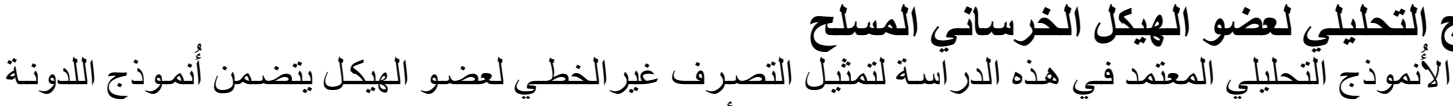

\section{الأُموذج التحليلي لعضو الهيكل الخرساني المسلح}

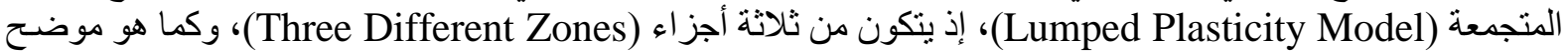

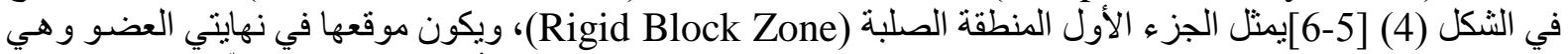

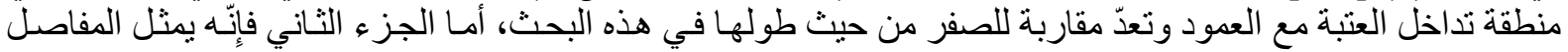




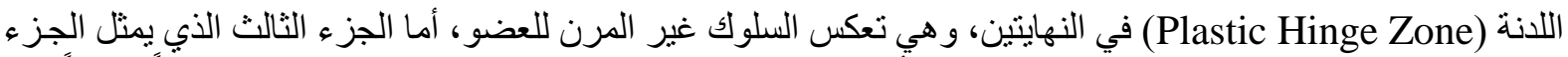

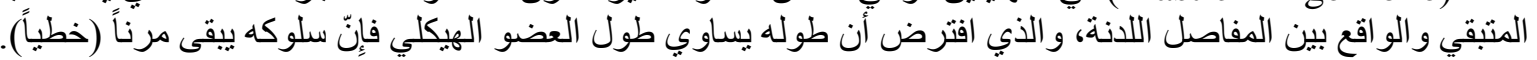

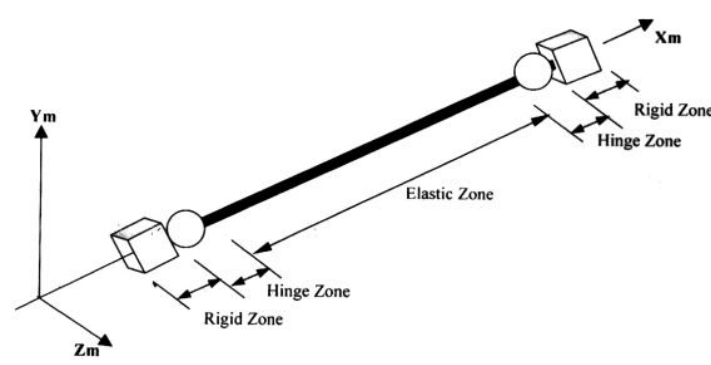

الثكل (4): الأنموذج التحليلي لعضو الهيكل الخرساني المسلح

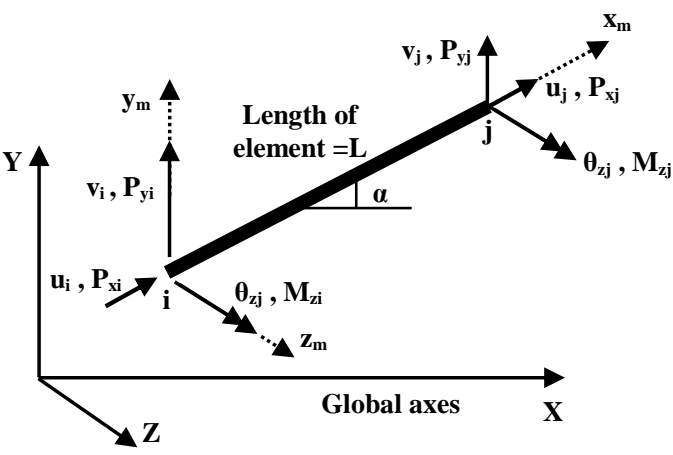

الثكل (3): الإزاحات والقوى في نهايتي

عنصر العتبة ــ العمود ذي البعدين في فئي

سطح الخضوع لعضو الهيكل الخرساني المسلح ذي البعدين

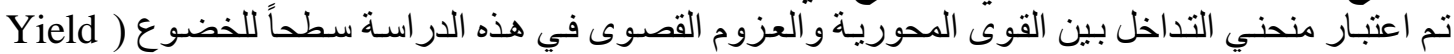

وurface ولحديد التسليح ولقضبان ألياف البوليمر و أبعاد المقطع، فضلاً عن كمية حديد التسليح وكمية قضبان ألياف البوليمر.

1- علاقة الإجهاد ـ الانفعال للخرسانة ولقضبان حديد التسليح ولقضبان ألياف البوليمر الكاربونية:

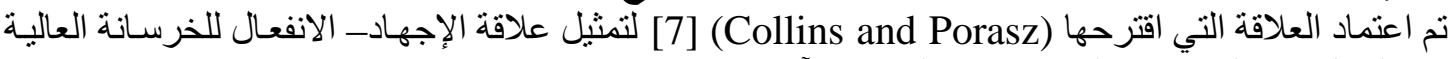
المقاومة الثكل (5) التي يمكن التعبير عنها بالصيخة الآتية:

$\sigma_{c}=f_{c}^{\prime} \times \frac{\varepsilon_{c}}{\varepsilon_{o}} \times \frac{n}{n^{-} 1+\left(\frac{\varepsilon_{c}}{\varepsilon_{o}}\right)^{n k}}$

Where

$\varepsilon_{o}=\frac{n}{n-1} \cdot \frac{f_{c}^{\prime}}{E_{c}} \quad, \quad n=0.8+\frac{f_{c}^{\prime}}{17}$

$k=1 \quad$ for the descending branch

$k=0.67+\frac{f_{c}^{\prime}}{62} \quad$ for the ascending branch

$E_{c}=3320 \sqrt{f_{c}^{\prime}}+6900$ for $21 \mathrm{MPa}<f_{c}^{\prime}<83 \mathrm{MPa}$

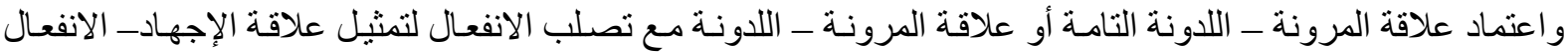
لحديد التسليح وكما موضح في الثكل (6) و التي يتم التعبير عنها بالصيغة التئة الاتية:

$\left\{\begin{array}{ll}\sigma_{s}=E_{s} \cdot \varepsilon_{s} & \sigma_{s} \leq f_{y} \\ \sigma_{s}=f_{y}+E_{s t} \cdot\left(\varepsilon_{s}-\varepsilon_{y}\right) & \sigma_{s}>f_{y}\end{array}\right\}$

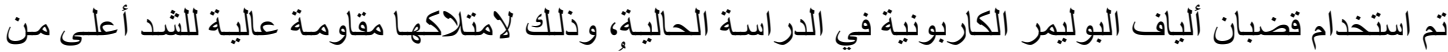

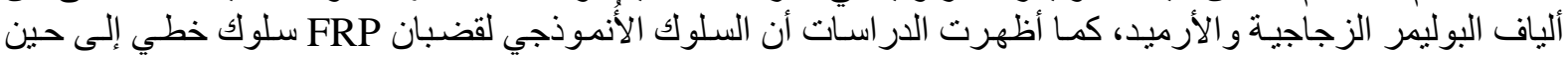




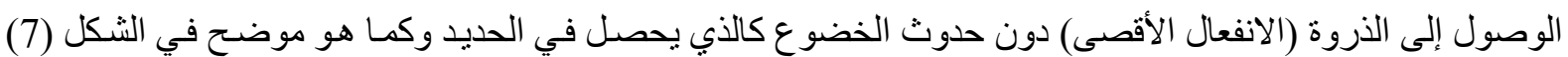

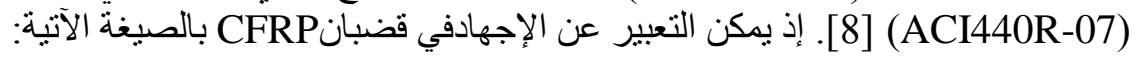
$\sigma_{f}=E_{f} \cdot \varepsilon_{f}$
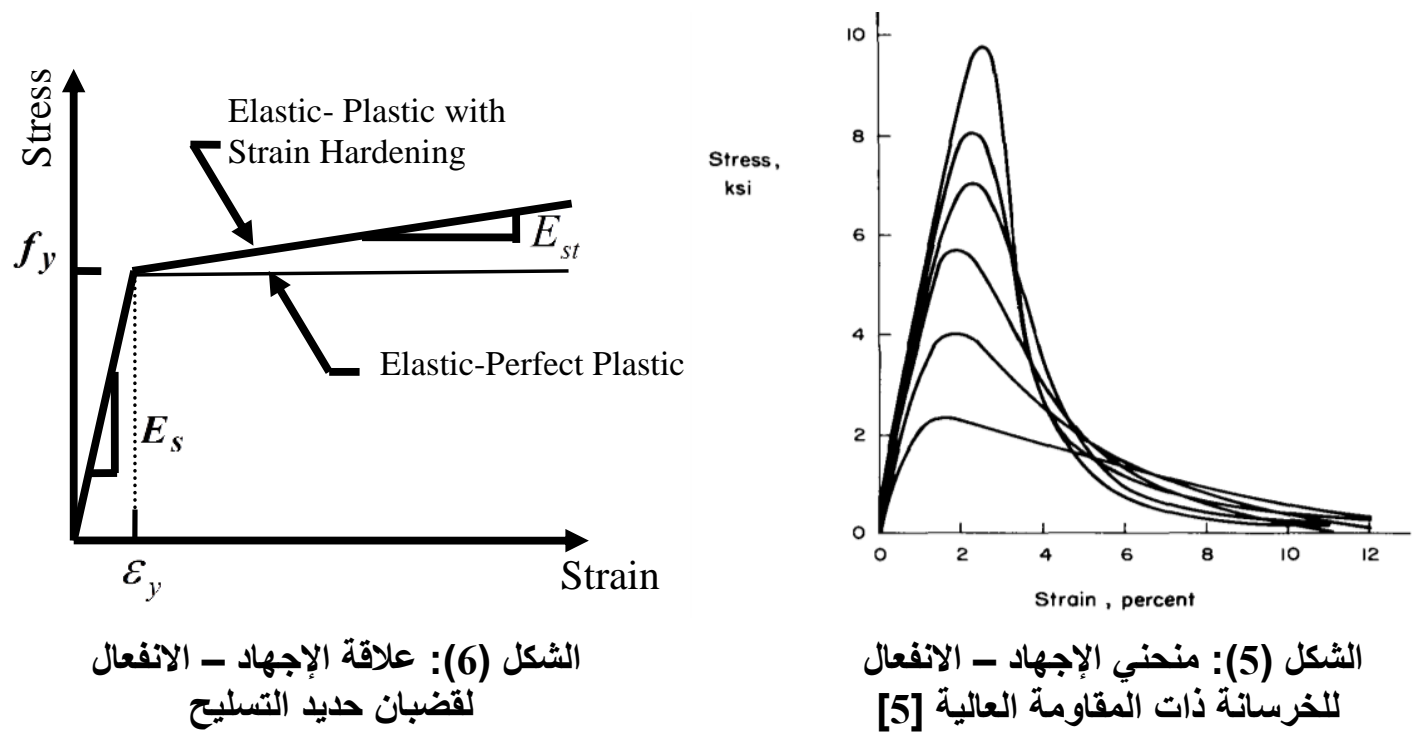

لقضبان حديد التسليح

الثكل (5): منحني الإجهاد - الانفعال

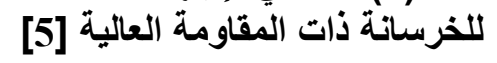

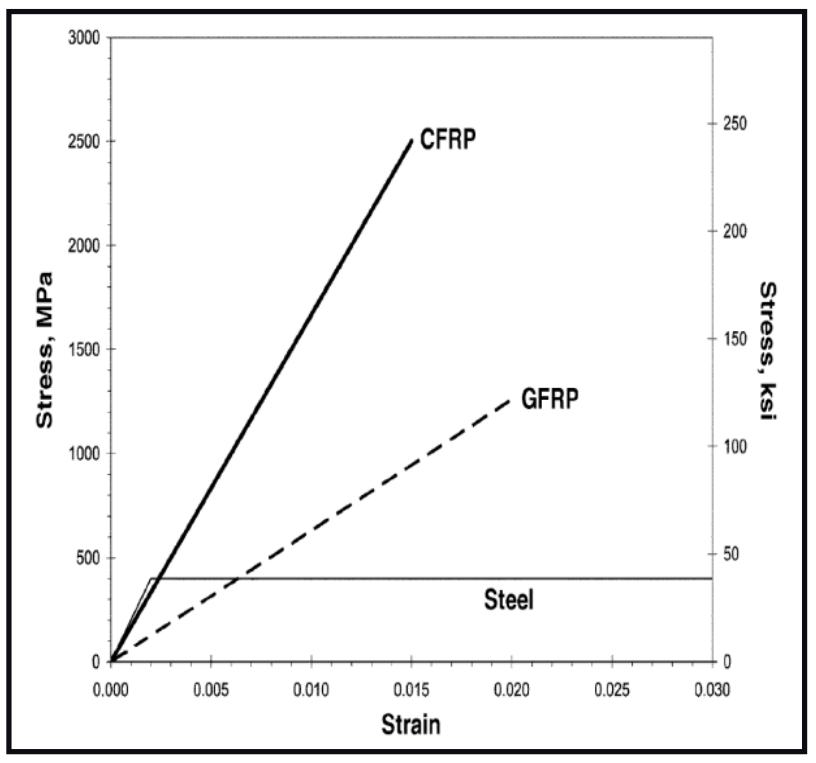

الثكل (7): علاقة الإجهاد ـ الانفعال لقضبان ألياف البوليمر CFRPP]

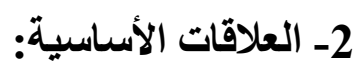

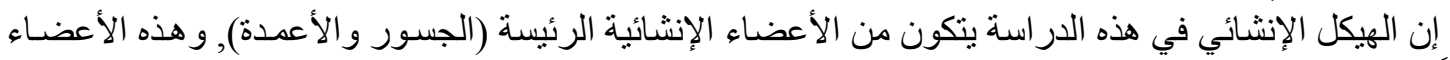

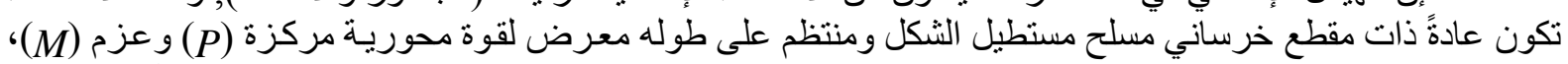

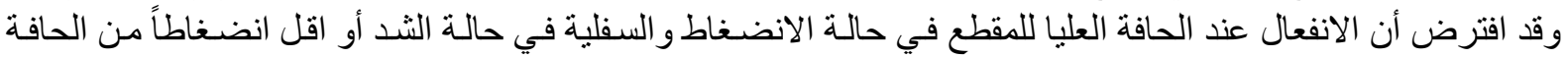

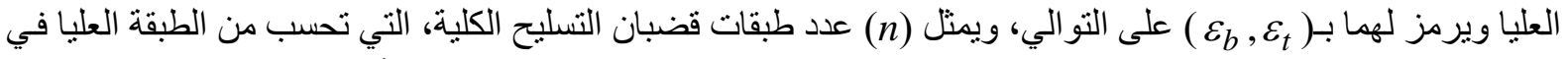

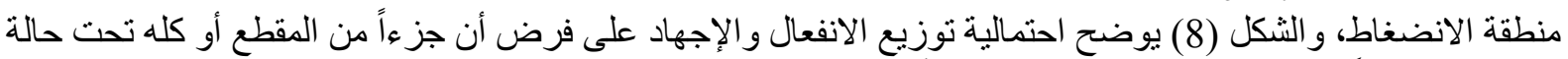

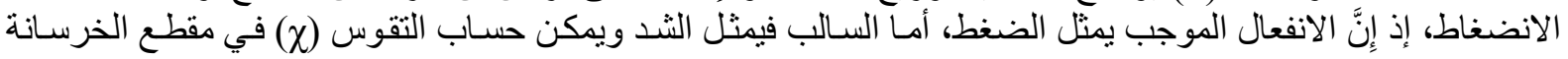




$$
\chi=\frac{\varepsilon_{t}+\varepsilon_{b}}{d}=\frac{\varepsilon_{t}}{k d}=\frac{\varepsilon_{s i}}{\left(k-\alpha_{i}\right) \cdot d}=\frac{\varepsilon_{c}}{y}=\frac{\varepsilon_{f j}}{\left(k-\beta_{j}\right) \cdot d}
$$

عندئذ يمكن كتابة معادلات التوازن للقوة المحورية والعزم (حول محور التعادل) بشكل صيغة غير بعدية

$$
p=\frac{1}{\phi} \int_{\varepsilon_{c}} \frac{\sigma_{c}}{f_{c}^{\prime}} d \varepsilon_{c}+\sum_{i=1}^{n} \rho_{s i} \frac{\sigma_{s i}}{f_{c}^{\prime}}+\sum_{j=1}^{2} \rho_{f j} \frac{f_{f j}}{f_{c}^{\prime}}
$$

كما يأتي التون (Non-dimensional form)

$m=\frac{1}{\phi^{2}} \int_{\varepsilon_{c}} \frac{\sigma_{c}}{f_{c}^{\prime}} \varepsilon_{c} d \varepsilon_{c}+\frac{1}{\phi} \sum_{i=1}^{n} \rho_{s i} \frac{\sigma_{s i}}{f_{c}^{\prime}} \varepsilon_{s i}+\frac{1}{\phi} \sum_{j=1}^{2} \rho_{f j} \frac{f_{f j}}{f_{c}^{\prime}} \varepsilon_{f j}-P\left(\frac{\varepsilon_{t}}{\phi}-0.5\right)$

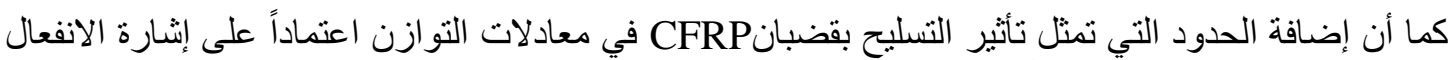

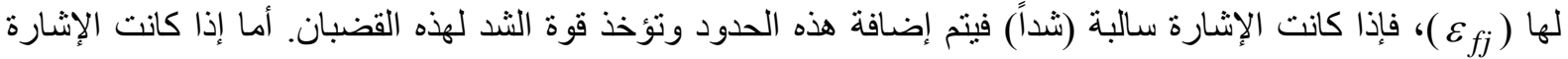

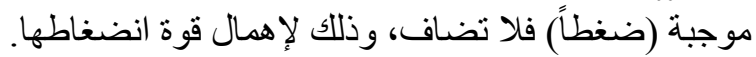

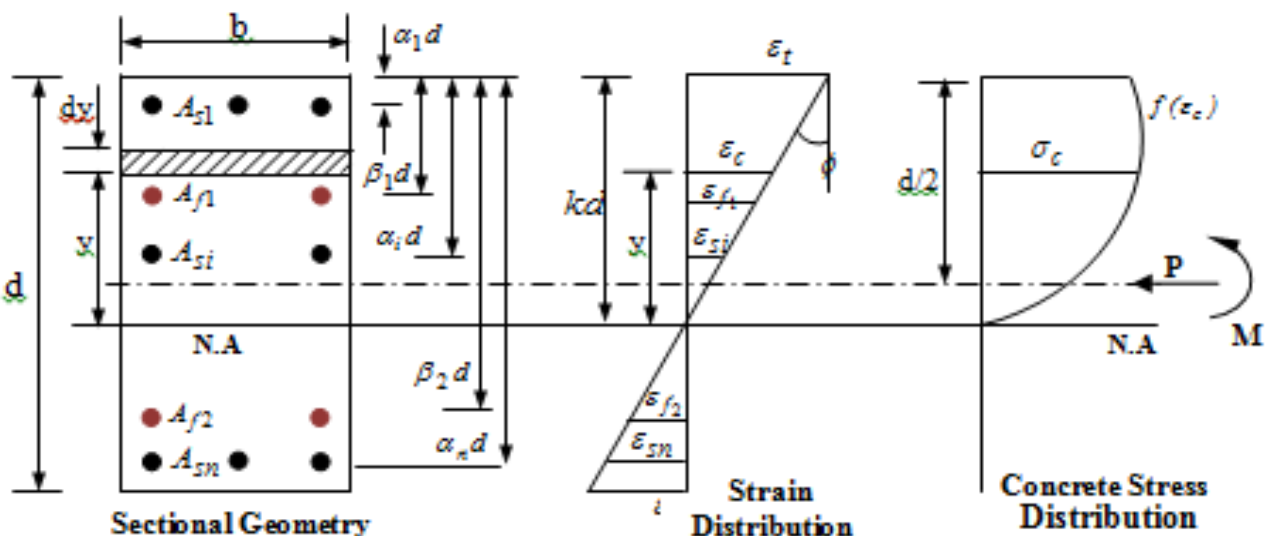
$\mathrm{e}_{\text {balance }}>0.0$

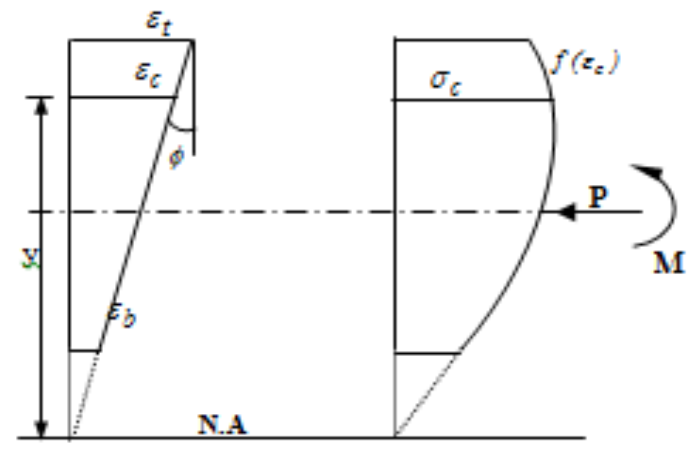

$$
\mathbf{e}_{\text {balance }}<\mathbf{0 . 0}
$$

الثنكل (8): الثنكل الهتبسي لهقطع الهيكل القربساتي المسلح

هي توزيع الإجهاد والاتقعال الثنال

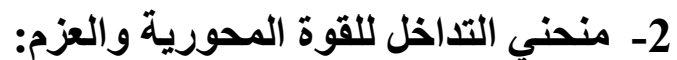

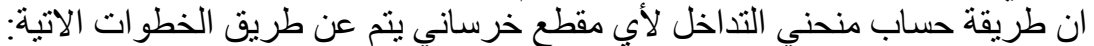
1-حساب قوة الانضغاط المحورية القصوى ( 
2-حساب القوة المحورية المنوازنة (Balanced Axial Load) (

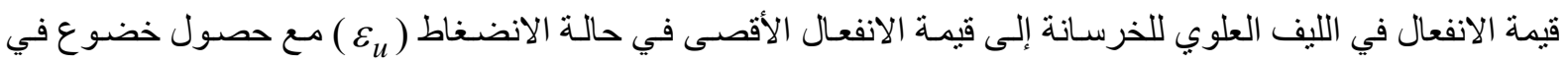
طبقة قضبان التسليح السفلية.

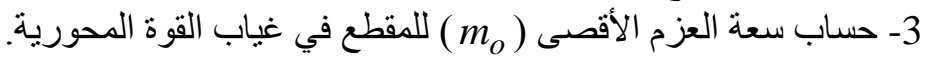

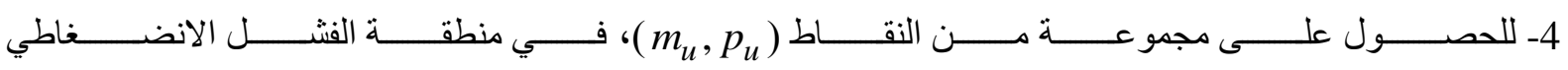
التي تكون بين (Compression Failure Region) . $\left(0.85 p_{o}, p_{u b}\right)$ 5- وفي منطقة الفشـل بالثـد (Tension Failure Region) تم اختيار قيم لـ (

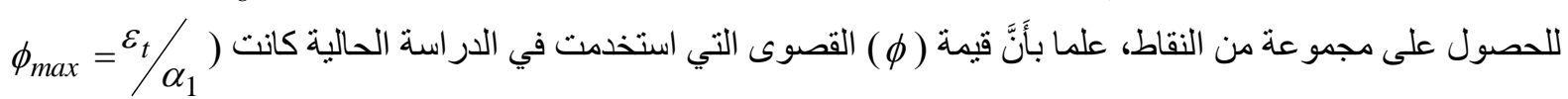

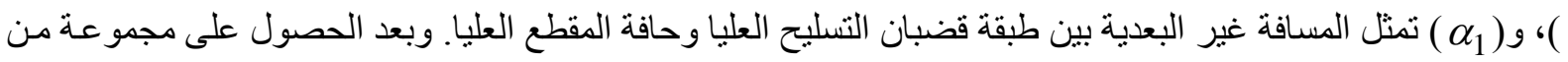

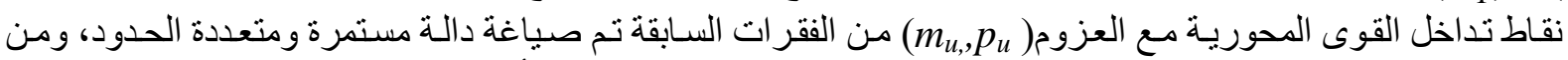

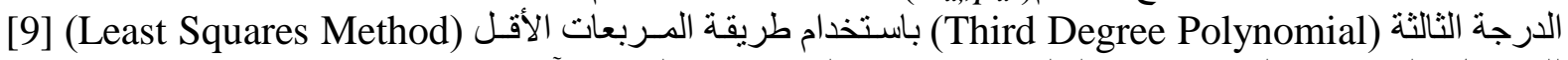
للحصول على منحني التو افق، و هذه الدالة يمكن كتابتها بالصيغة غير البعدية الآتية:

$\frac{m_{u}}{m_{o}}=a_{1}+a_{2}\left(\frac{p_{u}}{p_{o}}\right)+a_{3}\left(\frac{p_{u}}{p_{o}}\right)^{2}+a_{4}\left(\frac{p_{u}}{p_{o}}\right)^{3}$

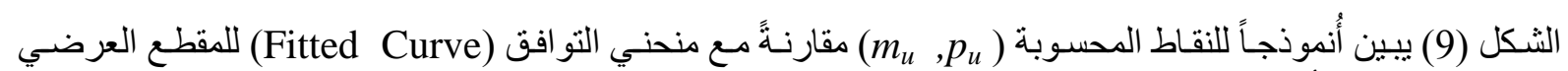
الموضحة تفاصيله أدناه، ويلحظ من الثكل التو افق الجيد بين النقاط الحقيقية المحسوبة ومنحني التو افق.

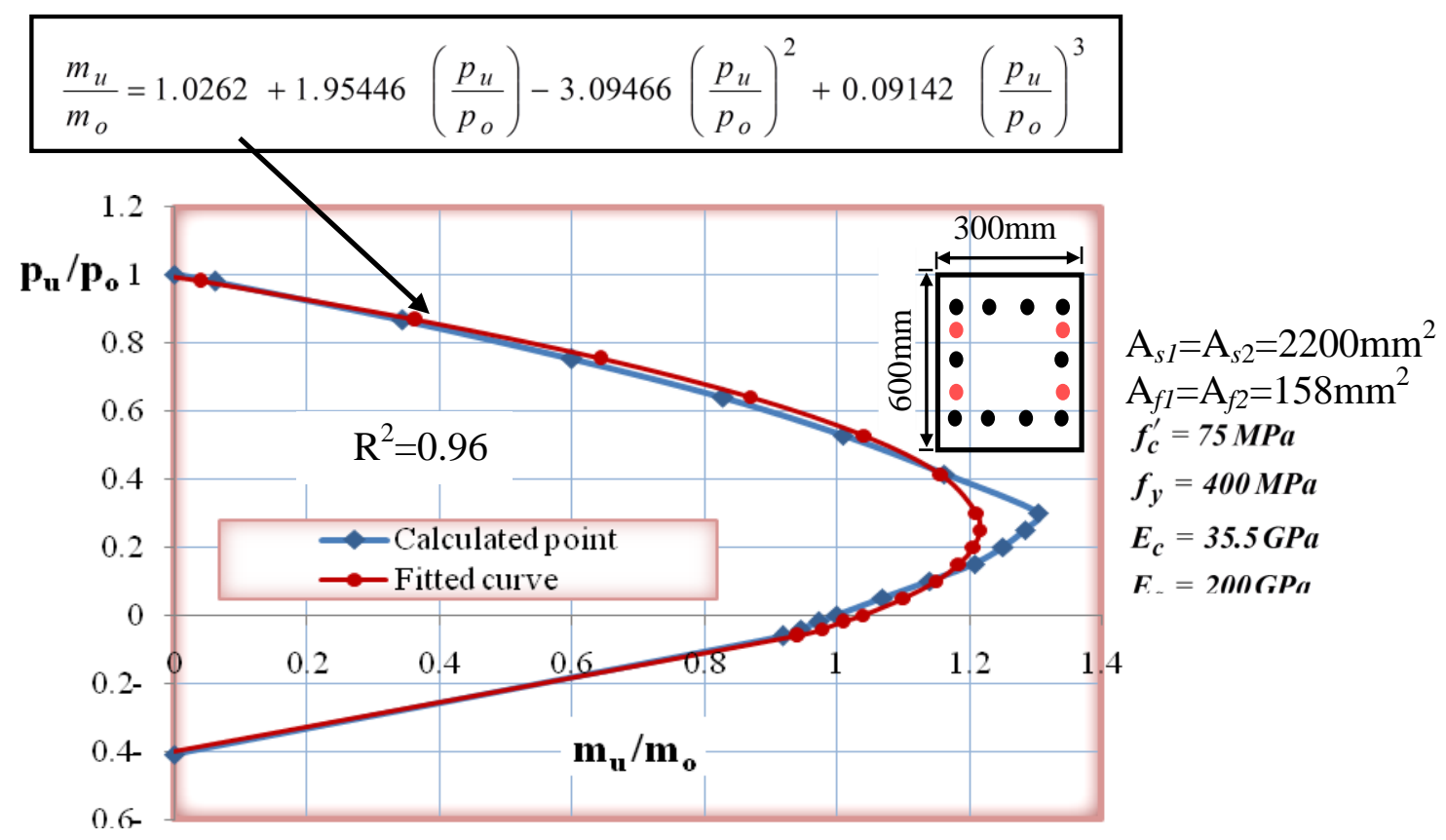

الثكل (9): يوضح منحنى التداخل الحقيقى والمتوافق للقوة المحورية والعزم

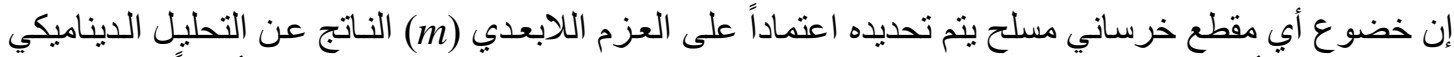

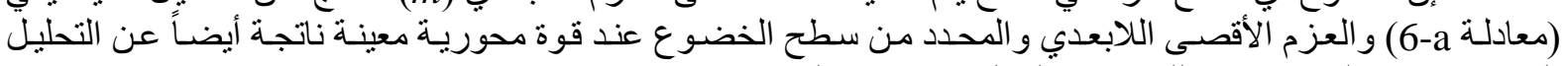
$f=\left|\frac{m}{m_{u}}\right|$ الديناميكي (معادلة b-6), و وبذللك تكون دألة الخضو الخدو كما يلي: 


\section{التحليل المرن-غير المرن}

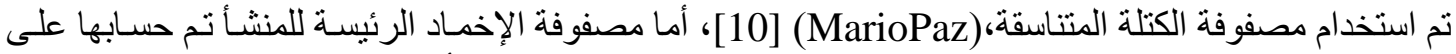

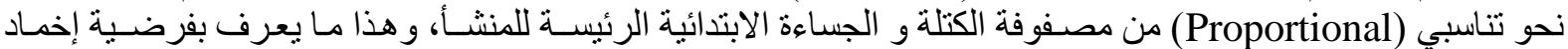

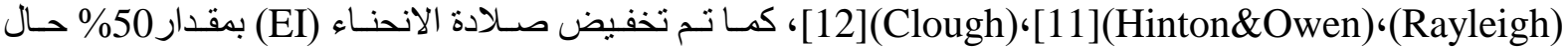

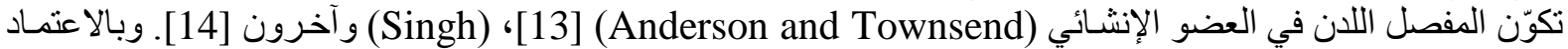

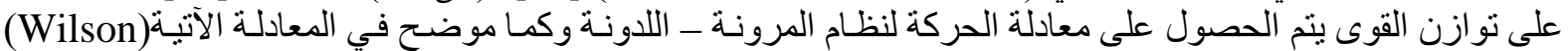

$M . \ddot{u}+K \cdot \dot{u}+C \cdot u=F$

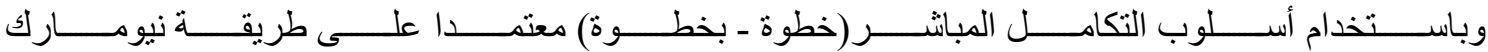

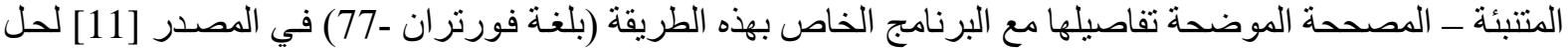

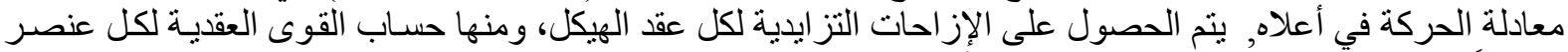

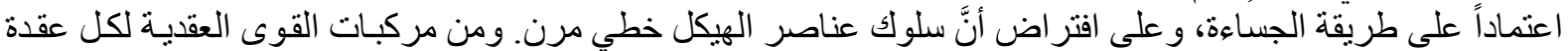

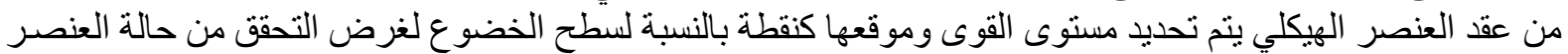

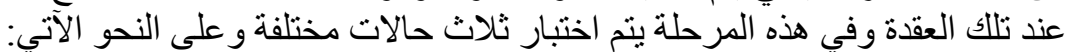

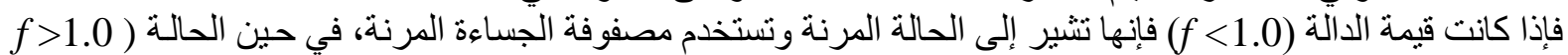

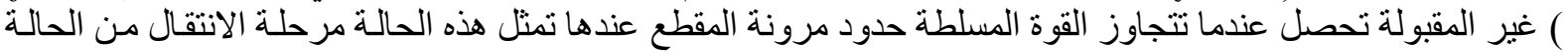

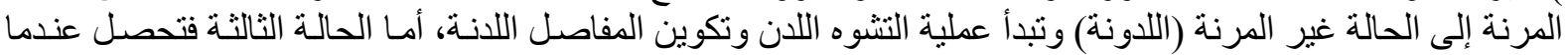
يكون هنالك مفصل لدن من الخطوة السابقة وفي هذه الحالة ينم اختبار موقع النقطة (التي تمثل القوة العقدية) نسبة إلى سطح

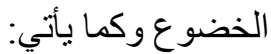

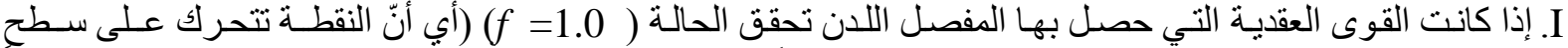

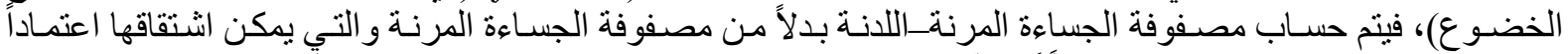

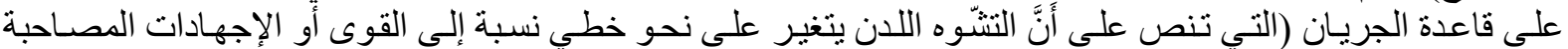

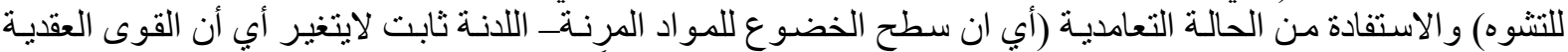

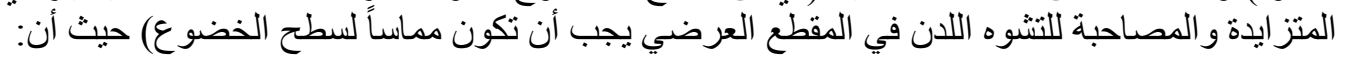

$\left[K_{e p}\right]=\left[K_{e}\right]+\left[K_{p}\right]$

لـي حالة كون (II

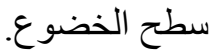

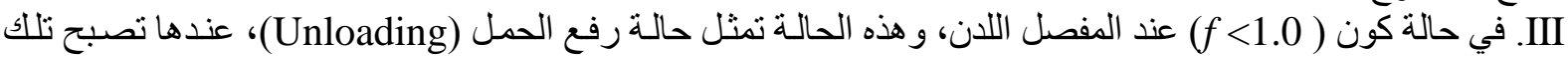
العقدة (المفصل اللان السابق) ذات سلوك خطي (مرن).

استجابة الهيكل الخرساني المسلح لحمل الانفجار

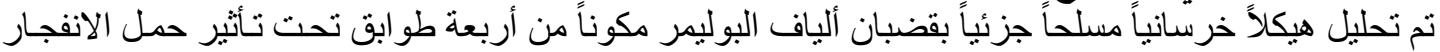

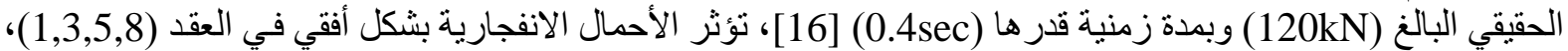

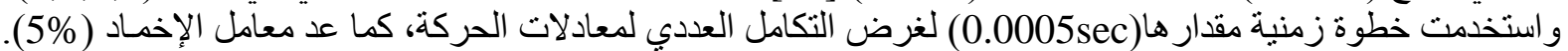

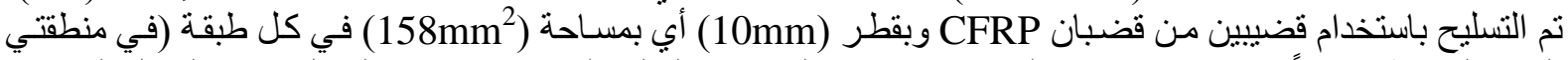

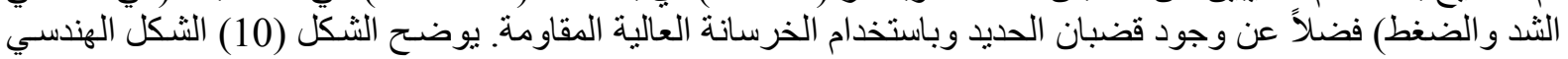
وخصائص المقاطع للهيكل الخرساني المسلح. 

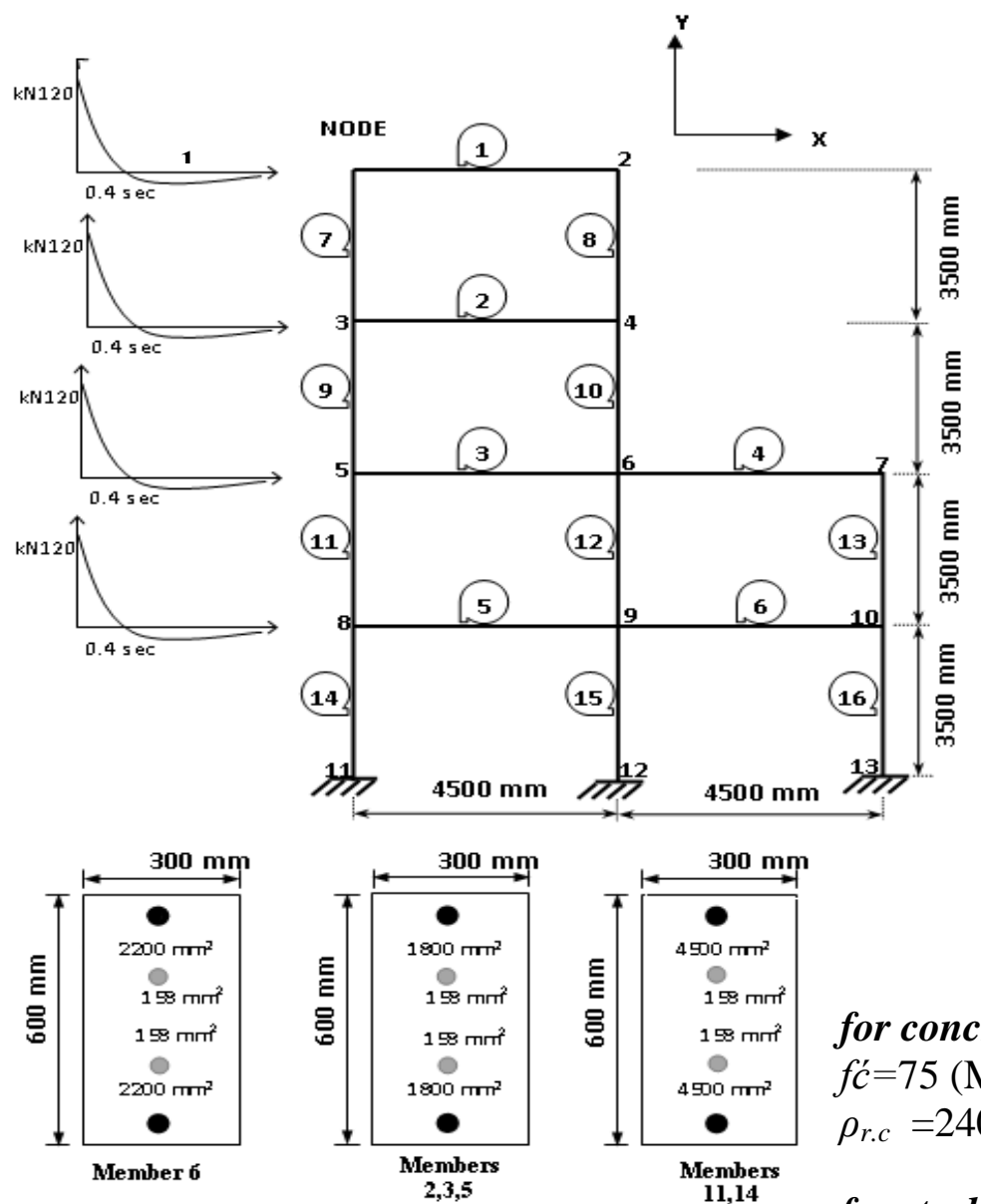

for concrete:

$f^{\prime}=75(\mathrm{MPa})$

$\rho_{r . c}=2400\left(\mathrm{Kg} / \mathrm{m}^{3}\right)$
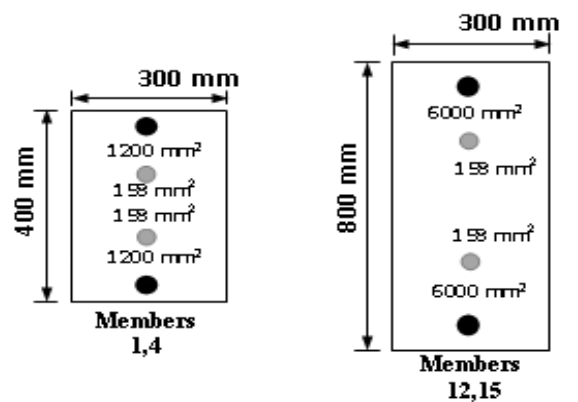

for steel:

$f_{y}=400(\mathrm{MPa})$

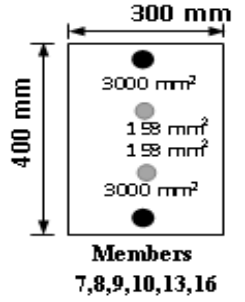

$E_{S}=200000(\mathrm{MPa})$

for CFRP rebars:

$f_{f u}=2500(\mathrm{MPa})$

$E_{f}=167000(\mathrm{MPa})$

الثكل (10):الهندسي وخصائص المقاطع للهيكل الخرساني المسلح

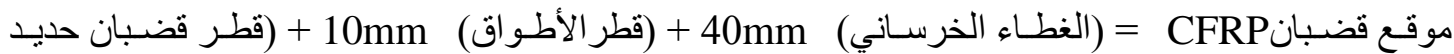

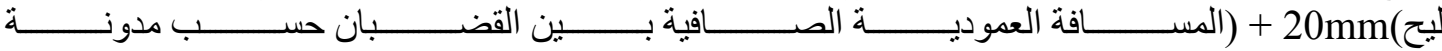

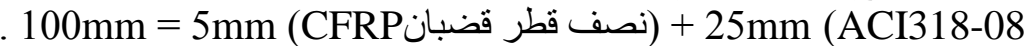

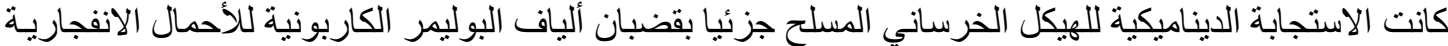

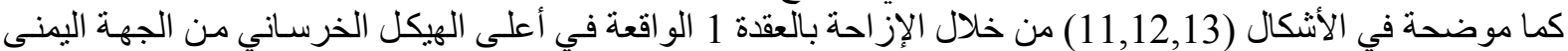

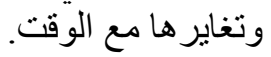




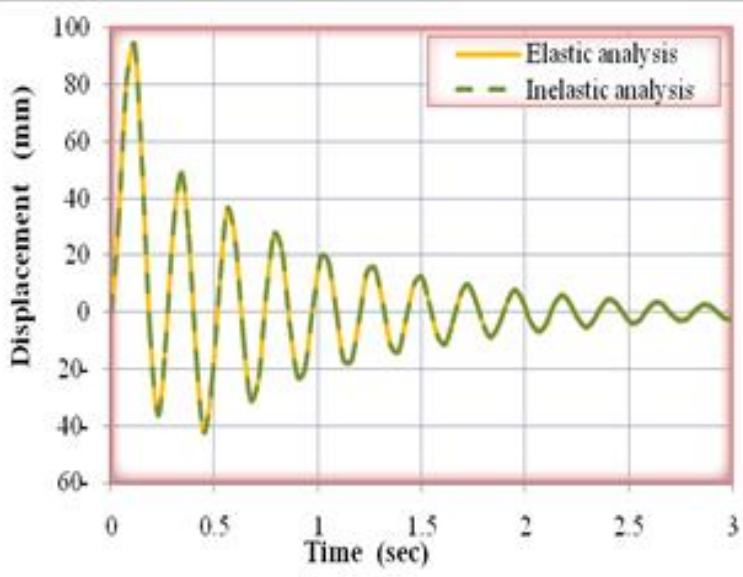

الثكل (12): تغاير الإزاحة الأفقية ميع الزمن للعقدة (1) عند التسليح بقضبان CFRP

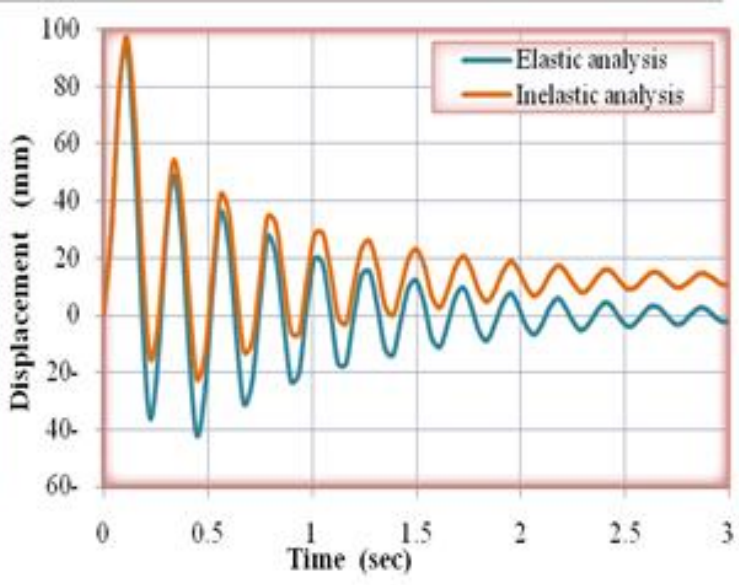

الثكل (11): تفاير الإزاحة الأفقية مي الزمن للعقدة (1)

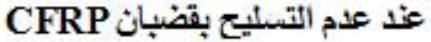

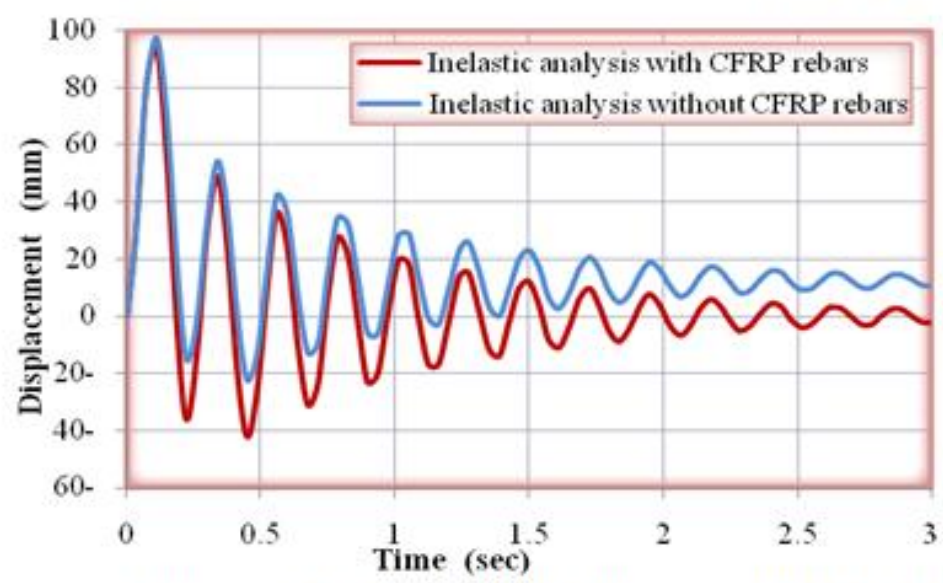

الثكل (13): المقارنة بين الإزاحة الأقية غير المرنة ميع الزمن للمثدة (1)

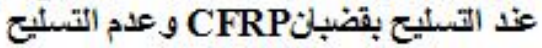

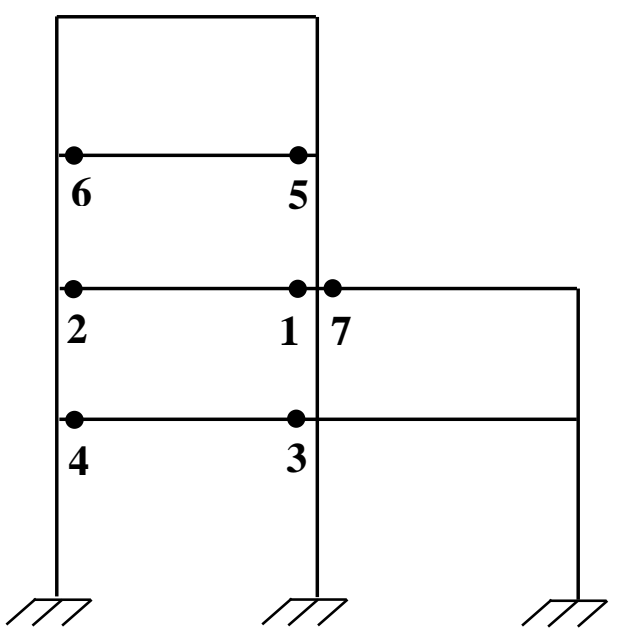

الشكل (14): مواقع تكّون المفاصل اللدنة

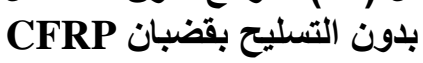

من الأشكال أعلاه بمكن ملاحظـة حصول تطابق تـام بين التحليل

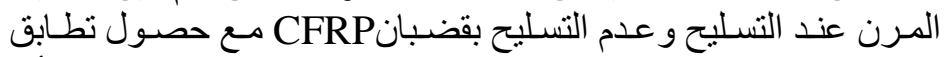

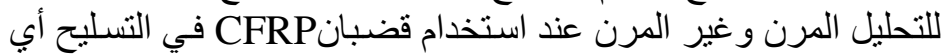

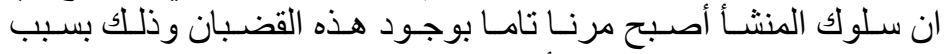

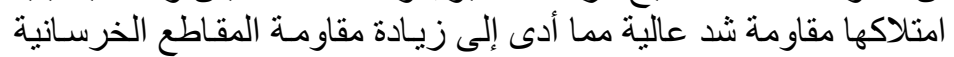

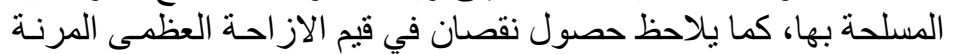

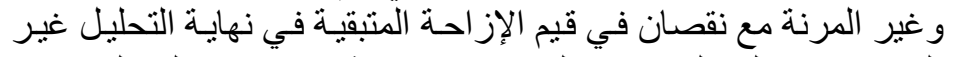

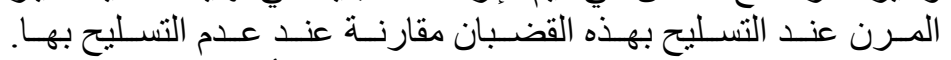

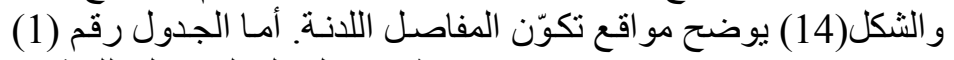

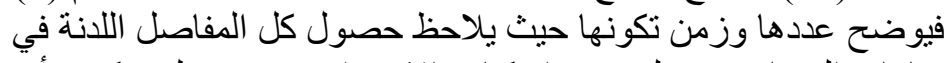

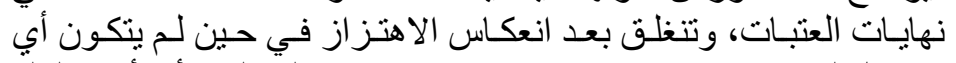

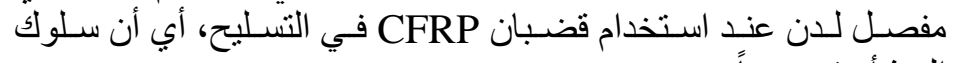
المنشأ ييقى مرناً. 


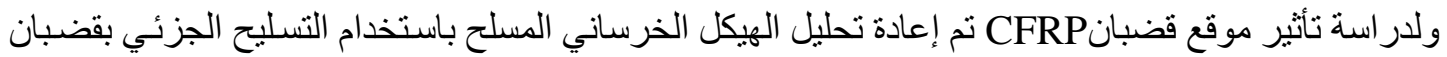

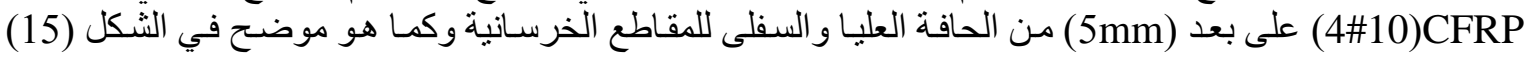

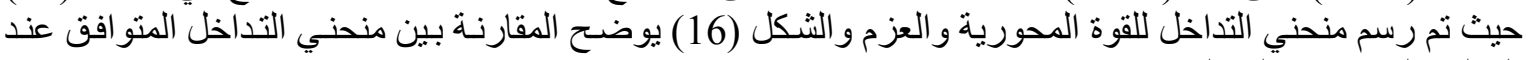

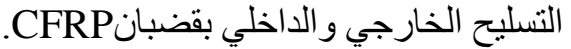

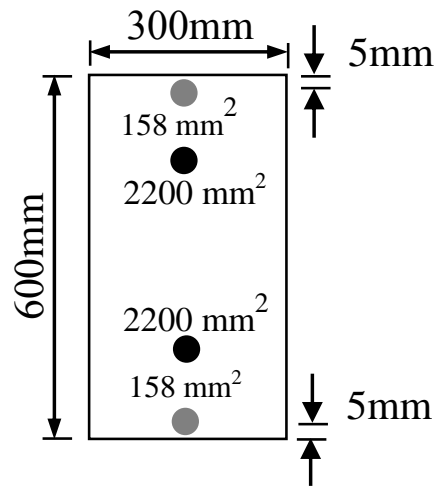

الشكل (15): يوضح تفاصيل المقطع

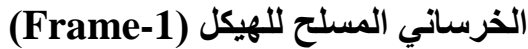
عند التسليح الخارجي بقضبان CFRP

الجدول (1): التكوين التتابعي للمفاصل اللانة

\begin{tabular}{|c|c|c|}
\hline \multirow{2}{*}{ اللانة المتكونة } & \multicolumn{2}{|c|}{ زمن تكوين المفاصل اللانة (sec) } \\
\hline & عند عدم التسليح بقضبان & $\begin{array}{c}\text { عند التسليح بقضبان } \\
\text { CFRP }\end{array}$ \\
\hline 1 & 0.068 & - \\
\hline 2 & 0.071 & - \\
\hline 3 & 0.0755 & - \\
\hline 4 & 0.0785 & - \\
\hline 5 & 0.0805 & - \\
\hline 6 & 0.0805 & - \\
\hline 7 & 0.104 & - \\
\hline
\end{tabular}

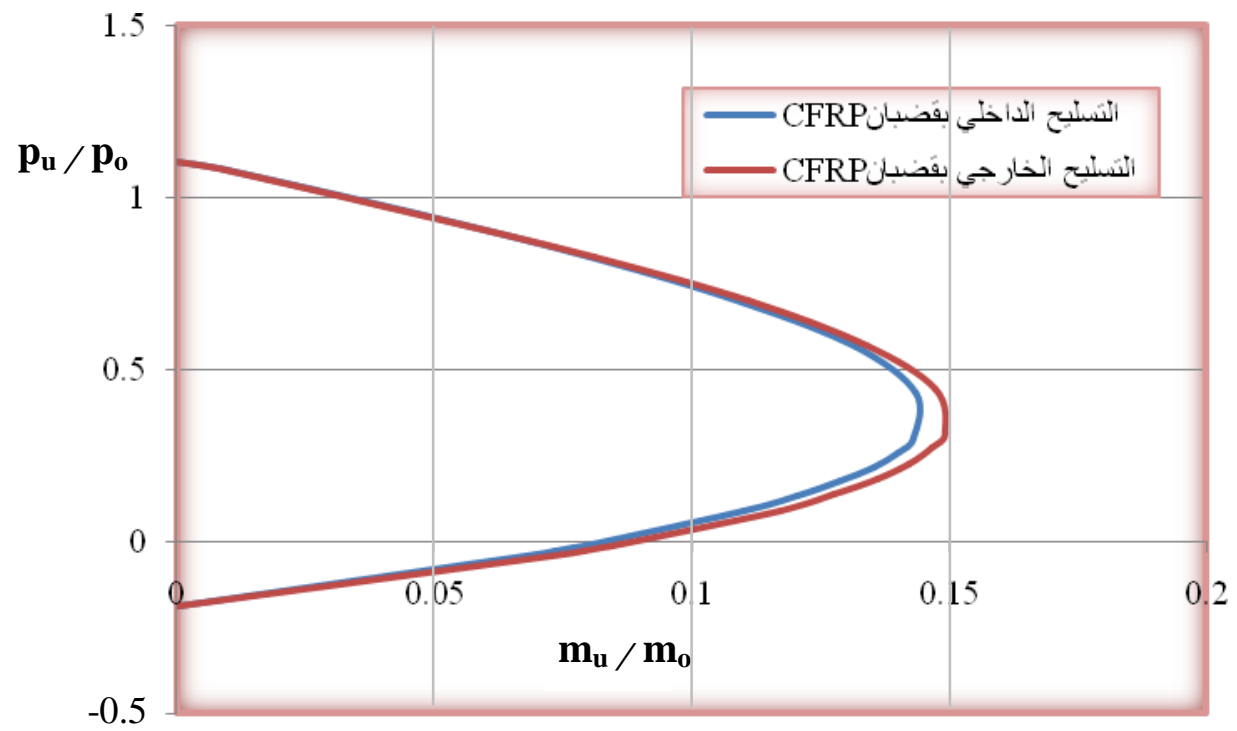

الثكل (16): يوضح المقارنة بين منحني التداخل المتوافق عند التسليح

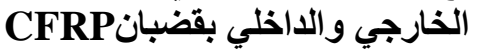

تم إجر اء تحليل ديناميكي مرنا وغير مرن باستخدام برنامج (SAP2000) باستخدام الخرسانة العالية المقاومة

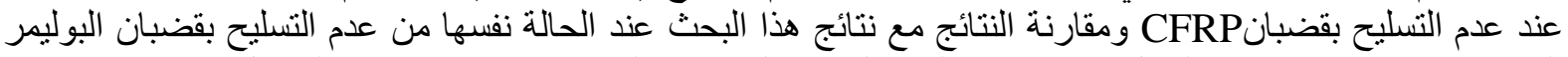

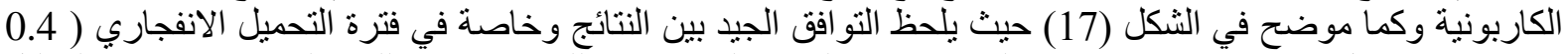

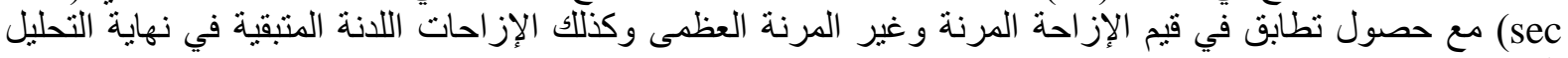



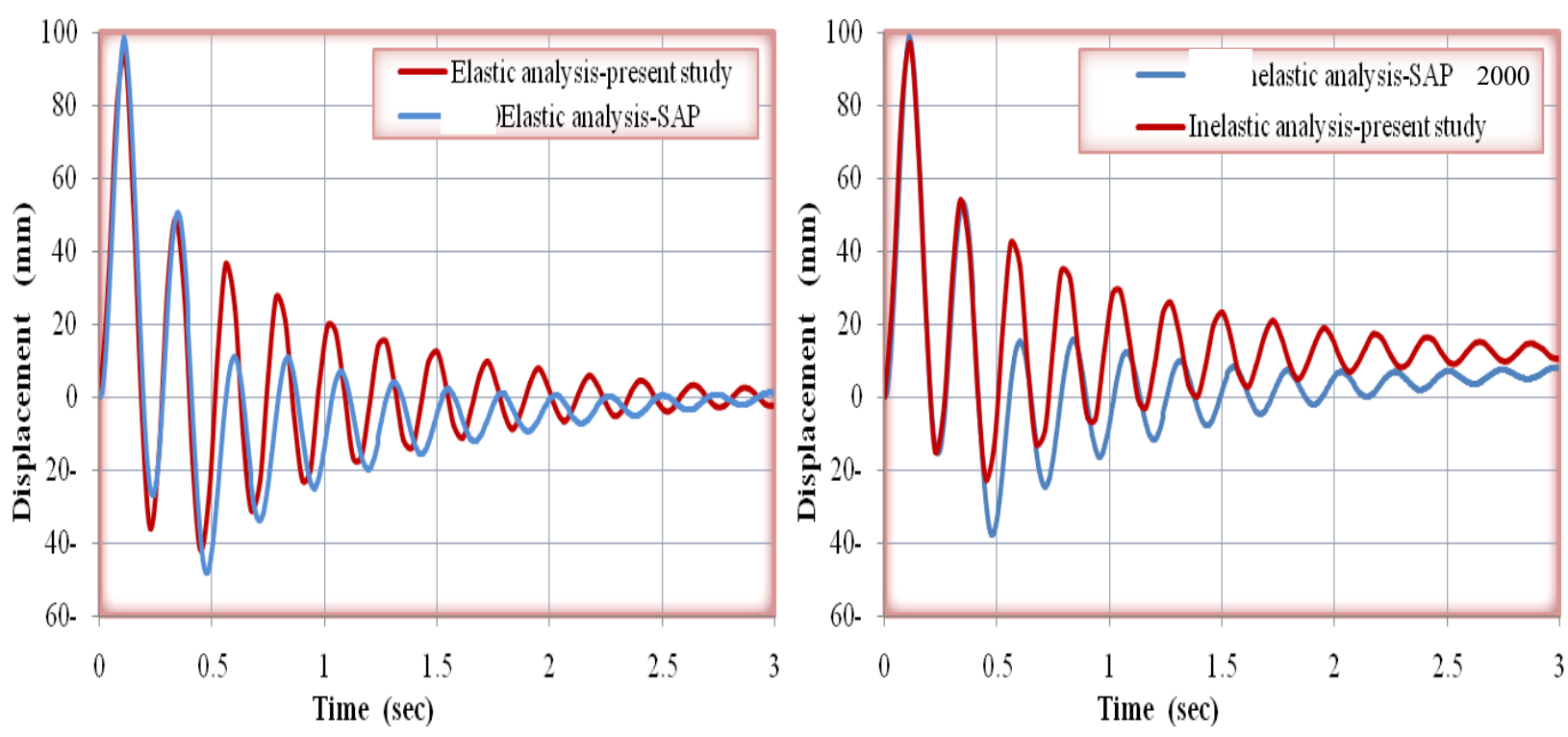

الثكل (17): يوضح المقارنة بين الازاحة الافقية المرنة وغير المرنة

للعقدة (1) باستخدام برنامج (SAP2000)

من خلال تحليل النتائج التي تم الحصول عليها يمكن وصف الخصائص الآتية:

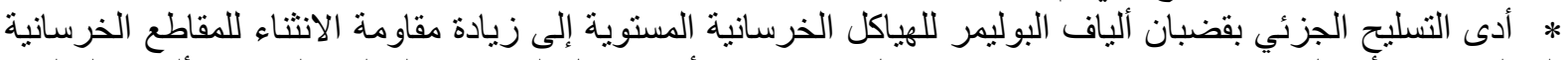

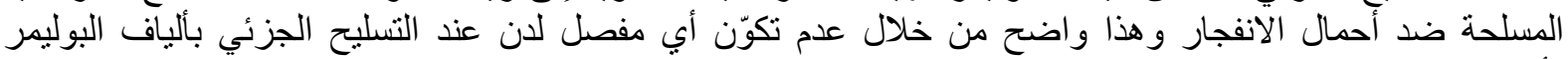

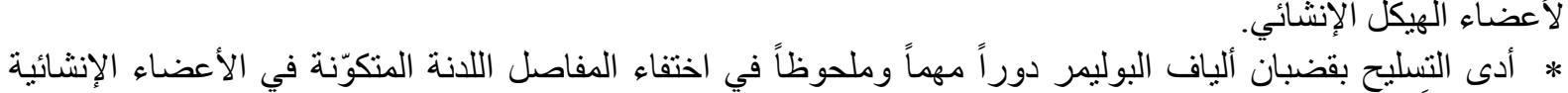

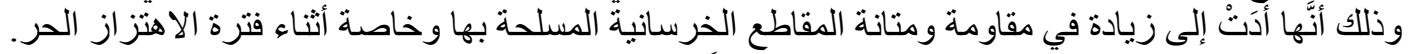

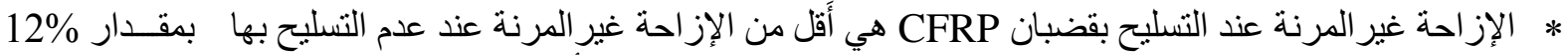

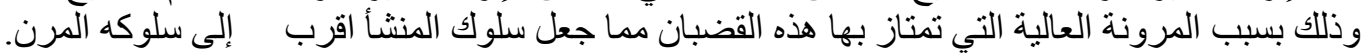

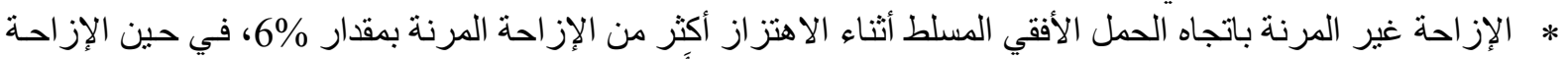

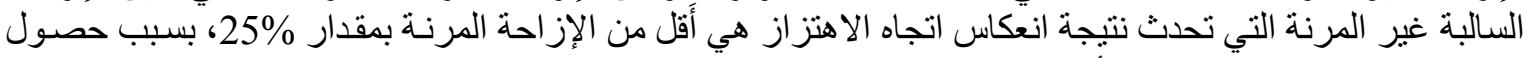

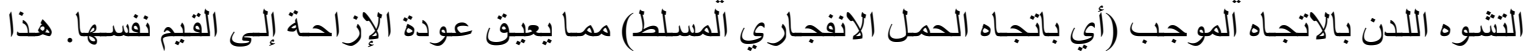

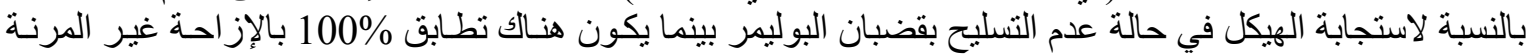

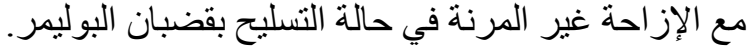

المصادر

[1] Grace, N.F., Soliman, A.K., Abdel-Sayed, G., and Saleh, K.R., "Behavior and Ductility of Simple and Continuous FRP Reinforced Beams", Journal of Composites for Construction, Vol. 2, No. 4, November, 1998,pp. 186-194.

[2] Lee, J. M., and Burgoyne, C. J., "Experimental Study of Influence of Bond on Flexural Behavior of Concrete Beams Pretensioned with Aramid Fiber Reinforced Plastics", ACI Structural Journal, Vol.96, No.3, May-June, 1999, pp.377-386.

[3] Choo, C. C. , "Investigation of Rectangular Concrete Columns Reinforced or Prestressed with Fiber Reinforced Polymer (FRP) Bars or Tendons", Doctoral Thesis, University of Kentucky, Lexington, March, 2005, pp.139.

[4] Rafi, M. M., Nadjai, A. , Ali, F., and Talamona , D. ,“ Aspects of Beha-viour of CFRP Reinforced Concrete Beams in Bending”, Science Direct Journal of Construction and Building Materials, 2006, pp.1-9. 
[5] Powel ,G. H. , Chen, P.F., "3D Beam - Column Element with Generalized Plastic Hinges”, Journal of Engineering Mechanics Division, ASCE, Vol. 112, No. 7, 1986 , pp. 627641.

[6] Al-Haddad, M. S., and Wight, J. K., "Relocating Beam Plastic Hinging Zones for Earthquake Resistant Design of R/C Buildings", ACI Structural Journal, Vol. 85, No. 2, 1988,pp. 123-133.

[7] Collins, M. P., and Porasz , A. ,"Shear Design for High-Strength Concrete",Comité Euro-International du Béton, Bulletind' Information ,No.193,1989, pp.77-83.

[8] ACI440R-07,"Report on Fiber-Reinforced Polymer (FRP) Reinforcement for Concrete Structures”, American Concrete Institute, 2007, pp.1-100.

[9] Kuo, S.S., "Computer Applications of Numerical Methods", Addison-Wesley Publishing Company, New-Hampshire, 1972 , pp.252-275.

[10] Mario Paz, "Structural Dynamics Theory and Computation", CBS Publ-ishers and Distributors in Arrangement with Van Nostrand Reinhold Company Inc., New Delhi, 1987.

[11] Owen, D. R. J., and Hinton, E., "Finite Element in Plasticity: Theory and Practice", Pineridge Press Limited, Swansea, U.K, 1980.

[12] Clough, R. W., and Penzien, J. , "Dynamics of Structures",3rd Edition, University of California, Berkeley, Computers and Structures, Inc., USA, 2003, pp.234-245.

[13] Anderson, J.C., and Townsend, W. H., "Models for R/C Frames with Degrading Stiffness", Journal of The Structural Division, ASCE, Vol.103, No. ST12,1977, pp.23612376.

[14] Singh, H. , Paul, D. K., and Sastry, V. V., "Inelastic Dynamic Response of R/C Infilled Frames", Computers and Structures, Vol.69, 1998, pp.685-693.

[15] Wilson, E. L. "'Three-Dimensional Static and Dynamic Analysis of Structures", A Physical Approach with Emphasis on Earthquake Engineering, Computers and Structures, Inc., Berkeley, California, 2002.

[16] Thanoon, W. A. , "Inelastic Dynamic Analysis of Concrete Frames under Non-Nuclear Blast Loading", Ph.D. Thesis, University of Roorkee, Roorkee, India, 1993, pp.242

$$
\text { تم اجراء البحث في كلية ألهنسسة = جامعة ألموصل }
$$

